\title{
IMPLICATIONS OF PARTICIPATIVE MANAGEMENT AS A FACTOR IN SUSTAINABLE PERFORMANCE: ANALYSIS OF ADVANTAGES AND FORMS OF MANAGEMENT APPROACHES WITHIN MOROCCO'S SME'S
}

\author{
Chadi SAKHY ${ }^{1 *}$ \\ Master in International Trade, Zhengzhou University, School of Business Zhengzhou, China, Email: \\ Chadisakhy97@gmail.com
}

*Corresponding Author: -

Email: Chadisakhy97@gmail.com

\begin{abstract}
: -
The purpose of this analysis is to examine the competitive advantages that can be generated by the application of participative management within the organization. Among the many approaches and technologies that have been applied to date, some methods and technologies have proven to be unsuitable for the current economic and social environment. At the same time, organizations are always looking for more competitive resources to apply innovation and novelty in this field. Through the test model, the results of the analysis refer to data from 93 small and medium-sized companies and 86 in Morocco. In general, managers who adopt participatory and inclusive management practices such as strategic awareness and employee involvement in the implementation of organizational goals have better employee satisfaction and engagement, especially better employee performance and participation, ultimately giving the organization a competitive advantage.
\end{abstract}

Keywords: - Competitive advantages, management, approaches, participative management, inclusive management, managerial culture.

\section{(ㅇ) $(\$)$}




\section{INTRODUCTION:}

The economic situation in recent years has undergone radical changes in terms of specific systems and management techniques. It has affected the balance of energy, capital, raw materials, and labor resources markets. The main factors behind these imbalances were: inflation, financial crisis, housing crisis, food crisis, fluctuations in natural gas and oil prices. These imbalances had the effect of reducing foreign capital which led to a decrease in the pace of economic development (Lupu A.-G, Lupu FA, 2012). Successful management of an organization is closely related to the strategy adopted to manage that organization and apply strategic management to achieve the mission and goals of the organization. Over time, it has been determined that regardless of the type or size of the organization, the degree of competitiveness of an organization in the competitive environment in which it operates, is directly proportional to the quality, objectivity, and clarity of the strategies that some the organization adopts and uses. The post-modern society is influenced by major changes that require new approaches of organizations to the environment and implicitly to the thought and practice of management.

hange imposes on organizational management a different rhythm, new rules, and requirements, provoking its regeneration, its discovery, its imagination, as well as its capacity for innovation and learning. In organizations at the beginning of the third millennium, critical resources are linked to intellectual capital, skills, intangible assets, tacit or explicit knowledge, organizational processes, and practices. As a result, the methods and skills needed to manage larger or smaller organizations will be completely different from those used in the past to increase performance and achieve success. Effective managers of knowledge-based organizations will be responsible for creating those organizational and managerial cultures where the promotion and implementation of cutting-edge models or ideas is an opportunity available only to those who are considered adventurous or creative. Today's competitive environment is characterized by constant turbulence that primarily influences the act of leading. This turbulence is caused by declining demand, poor product quality, intense growth in asset prices, especially real estate, and the emergence of competition with something better to offer.

The current economic environment is also characterized by a slower pace of economic development compared to previous years due to the decline in labor productivity, currency depreciation, and rising interest rates, and unemployment. Competitive advantage depends on managerial competence, brand image, marketing skills, product distinction, fructification of economies of scale, knowledge of market requirements on the possibility of using resource capital, and the control of transportation and distribution. Organization, sociology, psychological and managerial theories mostly started with the discovery of the importance of people and the social-human climate for the efficient functioning of an organization. Multiple analyses and researches have been devoted to this issue, gradually configuring the dynamics of the human factor of the organization and management. There is a strong tendency to use certain operating modes that allow the replacement of empirical descriptive management by certain regulatory and scientific means.

The current and future management and trends of the business environment in Africa, of all economic agents, have a very strong contextual determination than the situation in other parts of the world, due to the transition to a new economic, political and social system. Therefore, demonstrating, even briefly, some of the main processes governing the market economy in Africa, is a prerequisite for analyzing the management models applied to the current economic environment, forming the structure and functionality of organizations, understanding and improving their management in general. Firstly, as emphasized by most currents of economic thought, the market economy is a system characterized by the fact that the objective pursued by economic agents is to maximize the profit, management, and operation of organizations that are achieved through the predominant use of economic levers.

The emergence in theory and practice of a wide range of management modes is explained by the increase in managerial efficiency applying a particular mode of management or other, compared to companies where the management does not apply a consistent management mode. Mihaela Vlasceanu points out that: "the success of the organizations of the 21 st century will depend mainly on the search for, the discovery and the effective use of skilled managers or those multi-skilled workers, imaginative, full of curiosity, persevering, focused on ideas, able to encourage diversity, paying attention to the challenges of the environment, with a continuous readiness to transform a vision into reality" (Vlasceanu, Mihaela, 2003).

So how can managers in this new decade differentiate themselves by creating inclusive management strategies within their organizations to remain competitive? This analysis attempts first to improve the understanding of the requirements of participative management as a reliable element of sustainable competitiveness for organizations. Secondly, to determine the benefits that managers could gain from participative management through its methods. In doing so, awareness, employee involvement in the implementation of the organization's objectives, and managerial feedback will be our units of measurement to assess the degree of implementation of participative management in our sample not from the managers' point of view but from that of the employees. The rest of the article will have the following structure. The next section deals with the different management methods and techniques, followed by the means to carry out a good participative management strategy. We will end with a discussion of the results and aconclusion.

\section{Methodology :}

About a hundred currently known management methods and techniques are subject to a process of continuous improvement to respond to technological change and the growing demands of the beneficiaries of the activity carried out by the organization. Methods are generally classified according to several criteria: the intended use, the 
objective pursued, its nature, the management functions of the exercise in which they are mainly used, and also the management subsystems in which they are used. A distinction must be made from the outset between management methods and methods used in management. The latter are methods of an economic, technical, sociological, etc. nature, the use of which does not directly affect the content and form of manifestation of managerial relationships and processes. Typically, they belong to organizational management because of their effectiveness. For example the discovery matrix, brainstorming, value analysis, Monte Carlo method, etc.

The managerial approach or technique is a fundamental unit, and cannot be dismantled without eliminating it or modifying its form and function. Management techniques are generally intended to accomplish the managerial tasks assigned to one or more managers. Instead, management systems are broader than management methods or techniques and usually contain them in some form. One method that meets the requirements and is often used is the so-called leading method. It refers to how the manager uses the tools available and exercises authority over the elements at his disposal to use them wisely and effectively to achieve his objectives. Another method used is the management method in which the steps and elements are precisely designed and strictly organized in a functional complex that facilitates the exercise of elements of the managerial process, with consequences on the activity and work efficiency of one or more managers.

Leading methods are effective ways of making social work bear fruit, of directing efforts towards the achievement of set objectives. In economics, what matters is the style that the leader adopts to manage a company. Among the most important leadership styles are: autocratic, persuasive, consultative, and democratic.

The autocratic style involves how the decision-maker makes decisions without consulting his associates and subordinates and without taking into account their views and proposals. Continuing the enumeration, the persuasive style is how the manager makes decisions without seeking the opinion of his associates and staff, but does his best to implement their decisions and obtain their consent. In the same vein, the consultative style refers to the situation where the manager consults his staff and subordinates in making decisions. The democratic style is applied when the manager adopts the decision made after the approval of his colleagues and subordinates. Of the multitude of methods, techniques, and procedures currently in use, some are less adaptable to the current economic and social context. Among these methods, techniques, and procedures currently used are the CSROEPM synthesis, psychosociological and motivational leadership, the Harzburg synthesis, leadership through communication, etc.

The CSROEPM synthesis was developed by HW Bayliss and consists in synthesizing the most commonly used leadership methods in current management without bringing innovative elements. The name of the method is an acronym of the most important issues of the proposed system: Communication, Systems, Results, Objectives, Exceptions, Participation, Motivation. This method consists of determining what is inherent and basic in each of the available means and then bringing these issues together in a clear and harmonized whole. This always starts with communication because it influences and generates the communicative attitude that aims to create a participative attitude and to involve colleagues in the company's problems.

Nevertheless, the CSROEPM synthesis has two limitations: it does not take into account fiscal management and, in addition, the outcome is directly proportionate to the performance obtained. Also known as "collegial leadership" or the "Harzburg Model", the Harzburg Synthesis, shortened to SH, offers an alternative to the CSROEPM. It was theorized by the Harzburg Management Academy. This practice consists of combining methods of leadership by objectives, exceptions, and results in a system that seeks cooperative relationships, shaping and defining the function of collaborator and confining the function of a leader, training the staff to a new conviction, delegating the ability to decide, etc. One recommendation of the Harzbug synthesis is to increase the use of empowerment, which ought to be disclosed at the time the decision can be made in the most enlightened way, which certainly does not mean by the most appropriate, but by the most informed.

The psychosocial and motivational method of leadership aims at the dynamism of the group and its motivation. This method consists in encouraging the staff not to stop only at fulfilling the requirements of their work but to use their skills to reach their potential to solve the different problems that arise in the organization. Among the less new leadership methods that are widely used in practice are: evaluation methods (SWOT analysis, etc.), meetings (information, decision, harmonization, exploitation, heterogeneous meetings), delegation, dashboard, business plan, brainstorming, Synectics method, Delbecq method, Delphi method, etc. The table below, which is a result of my survey, allows us to appreciate the degree of involvement of employees within their organizations.

Table 1. Structure of the Participatory Management Variable a) Strategic Awareness:

-Question: Does an organization develop strategic plans and are employees aware of them?

\begin{tabular}{l|ll} 
NO. & ANSWER OPTIONS & SCORE \\
\hline $\mathbf{1}$ & Strategic plans are developed for each business area. & 5 \\
$\mathbf{2}$ & A strategy is known to the employees. & 4 \\
$\mathbf{3}$ & The strategy is known only to the managers. & 3 \\
$\mathbf{4}$ & Some general long-term plans are developed. & 2 \\
$\mathbf{5}$ & Planning refers to periods of one year or even shorter. & 1 \\
$\mathbf{6}$ & An organization carries out daily activities. & 0
\end{tabular}


b) Goal-setting process :

-Question: Does an organization set operational goals for specific departments, teams, or employees?

\begin{tabular}{|l|cc}
\hline 1 & Employees participate in a goal-setting process. & 5 \\
2 & Goals are set by senior management in the form of a plan to achieve. & 4 \\
3 & Supervisors set goals for the nearest period. & 3 \\
4 & Supervisors express only general expectations of employees. & 2 \\
5 & Employees are expected to perform their duties. & 1 \\
6 & Employees do not have a defined scope of work. & 0
\end{tabular}

c) Managerial feedback:

-Question: Are meetings held to discuss organizational performance

\begin{tabular}{l|ccc}
\hline 1 & $\begin{array}{c}\text { Employees participate in regular meetings with } \\
\text { management or }\end{array}$ & 5 \\
2 & Supervisors discuss their performance with employees. & 4 \\
3 & There is an annual meeting with a performance \\
presentation. & 3 \\
4 & Employee briefings are held. & 2 \\
5 & Meetings include only management. & 1 \\
6 & No such meetings are held. & 0
\end{tabular}

Source: Made by the Author

Kim (2002) stated that a person involved in strategic decision-making can influence his or her work environment in the broadest possible way. A degree of participative management was also conditioned in the study by involvement in goal setting. One of the components of participative management: managerial feedback reflects the integration of employees in the reflection on company performance in such a way that discussions are not supposed to include only briefings where annual results are presented but are supposed to allow employees to express themselves. According to Detert and Burris (2007), although employee voice "can challenge and disrupt the status quo of the organization and its power holders, [it] is essential to organizational well-being." Therefore, it is necessary to create conditions where the benefits of having a voice are not outweighed by the risks that result from complex human relationships within an organization (Detert and Burris 2007); (Pitkänen and Lukka 2011). Emmert and Taher (1992). Employees who positively evaluate their work environment and easily communicate with peers and superiors should demonstrate greater job satisfaction and commitment than those with negative perceptions of both.

\section{Ways to Lead Participation:}

Currently, participative management is an efficient, effective, and modern management system. It can only be practiced with great results if there is a tendency towards a common goal by all employees of an organization, regardless of their hierarchical position within the organization. In this situation, the fundamentals are created that are necessary to establish the medium and long-term objectives and program by consensus, to base the decisions, and to put them into practice. Due to the accelerated changes like goods and services, the organization must focus its attention on the market segment, not the product. "A business is not defined by its name, charter or bylaws, but it is defined by the need that a customer meets when purchasing a product or service provided by the business." The question, "What is our business? can only be answered from a perspective that allows us to look at this business from the outside, that is, from the point of view of the consumer or the market segment" (Drucker, PF 1999). In management terms, participation is the activity by which employees of an organization take part in the management process, becoming involved both in the definition of objectives and in their effective and efficient implementation in practice. Participation is a combination of two specific actions: involvement and integration.

Today's managers must be able to cope with the many complex changes in the economy, such as social ties, demographic changes, and activities to promote internal development and acquisitions. Strategic planning allows managers to know what challenges and opportunities lie ahead. Because of the close dependencies amplified in the external environment of organizations, today's management can no longer make decisions based solely on internal or domestic considerations, as it must constantly consider laws, public opinion, shareholder wishes, labor ties, and other external parties. Otherwise, the needs or requirements of customers must be the top priority in developing the organization's mission because "an organization is distinguished by the quality of the products that satisfy the customers' requirements" (Drucker, PF 1993).

Participative management encourages the development of creativity and innovation so that the members of the organization see it as a challenge to achieve the best results. At the same time, participative management aims to motivate staff to provide quality services by appreciating the merits they have had after some interesting ideas and proposals and to push them towards advanced knowledge through self-improvement and training. It is mainly envisaged to reward and encourage the contribution of members to the improvement of organizational 
performance which is contained in the strategic objectives of the organization. Objectives such as increasing the profitability of the company, the competitive advantage held by the company, and market share are just some of the aspects of competitive advantage.

On the organizational level, it contributes to economic efficiency with levers such as: involving the company's staff in the decision-making processes, creating favorable conditions for employees that aim to facilitate participation in important decisions related to the prosperity of the company, the design and preservation of the strategic advantage through team spirit, a factor that is enhanced by the competitive skills of the staff. To achieve superior performance, there must be common goals, constructive criticism to encourage the development of individual skills and there must also be a superior supervisor who must be an example for the company's staff and must motivate them to achieve an optimal degree to reach maximum performance.

The main objective of the participatory management system is to strengthen management skills, to adapt future leaders to the problems that may arise, and to stimulate the ability to solve them through creative methods. Precarious leaders fail to support participative management for two reasons: either they aspire to have taken control of everything, or they fear being replaced by someone more competent.

Only strong leaders can instill courage and confidence in others by giving them responsibility and creating competent teams that bring success and prestige to the organization. The implementation of participatory management has advantages such as increasing the quality of decisions through the use of knowledge and managerial skills of the members of the company, improving the participation of stakeholders in the definition and achievement of the company's objectives, and raising the awareness of the members of the organization.

The use of participative management leads to the formation of competencies within the organization that will facilitate the introduction of transformation, change, permanent innovative practices, and the increase of organizational performance. In an organization where the organizational culture and work climate are strong, employees work together effectively, share the vision and mission of the organization and make joint efforts to create appropriate working conditions for each employee.

\section{Facts and Implications:}

a) Strategic Awareness:

The first-factor analyzed-strategic awareness-indicated whether strategic plans were formulated and whether employees were kept informed of these plans in the companies examined (fig.1).

\section{Figure 1: Strategic Awareness in Moroccan SMEs}

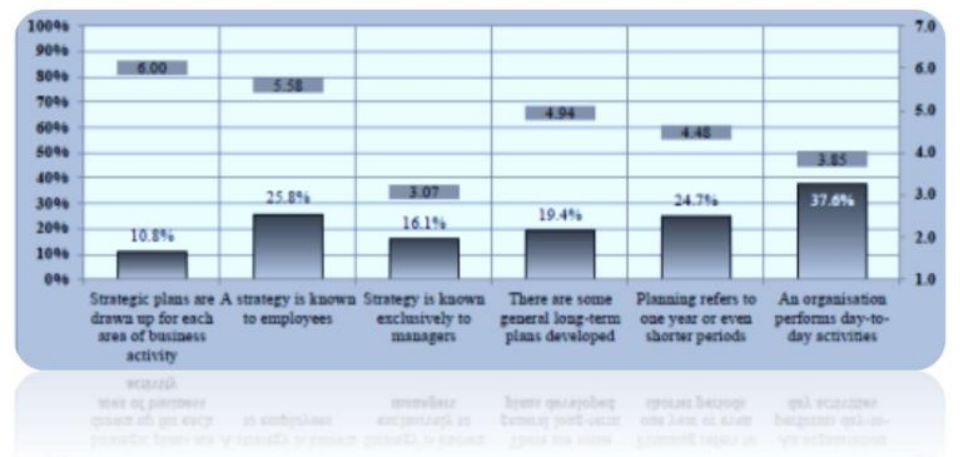

Source: Made by the Author

The first two response options reflected situations where employees were aware of strategic plans either for each area in which an organization operated or for a company as a whole. These two scenarios were reported together by $28.0 \%$ of SMEs. Familiarizing employees with a company's strategic plans proves that managers trust their staff, which intensifies employees' affiliation with the company. This bodes well for future business development. The above-mentioned scenarios were appreciated by the employees, who gave them satisfaction scores of 6.0 and 5.6 respectively. It should be added that in $62.8 \%$ of large companies, employees were fully aware of the business strategies.

The third option presented a situation where employees were aware of the existence of a strategy in a company, but this strategy was not revealed to anyone other than managers. Such a scenario was reported in $16.1 \%$ of SMEs and $31.4 \%$ of large companies. Interestingly, in the latter group, this was perceived as neutral, while for SMEs it was perceived as negative. Based on the descriptive responses, it can be concluded that in some large companies, employees felt that strategic issues should be left to senior management, as these topics were beyond the scope of regular employees. In smaller companies, the lack of information was associated with an uncertain future and made staff uncomfortable. Taking into account the three response options mentioned above, it can be stated that strategic plans were developed by $40.9 \%$ of SMEs and $86.0 \%$ of large companies. If also the fourth scenario (representing "a long-term path plan") was included, it appeared that more than half (51.6\%) of the SMEs considered issues beyond current operations in their planning. For large firms, this figure was $91.9 \%$, showing a huge gap in strategic thinking between Moroccan SMEs and large firms. 
Finally, an option where companies were only conducting routine transactions was chosen by 37.6\% of SMEs. In the majority of cases, this was the only response given. This meant that in one out of three Moroccan SMEs, not only were employees unaware of a business strategy but even the managers or owners did not seem to be aiming very far. This temporary nature was seen as slightly negative.

\section{b) Process for setting objectives:}

In addition to strategic awareness, methodologies for formulating operational goals were analyzed (Fig. 2). In most cases, SME employees felt that they were expected to perform their duties. In many cases, said response reflected a situation in which employees were performing routine, repeatable tasks without specific goals or targets defined. Employees in 24.7 percent of SMEs reported that they were not given formal goals or tasks to complete. Even general expectations were not expressed by their supervisors. Surprisingly, the situation described was seen as positive, with a possible explanation that employees felt they knew what they were doing and did not expect anything positive from the scrutiny of their work by managers. In the case of large companies, employees also frequently reported that they were expected to perform their duties. But in only $9.3 \%$ of firms was this the only way to organize work. In addition, one such situation was considered negative.

\section{Figure 2: Process for setting objectives}

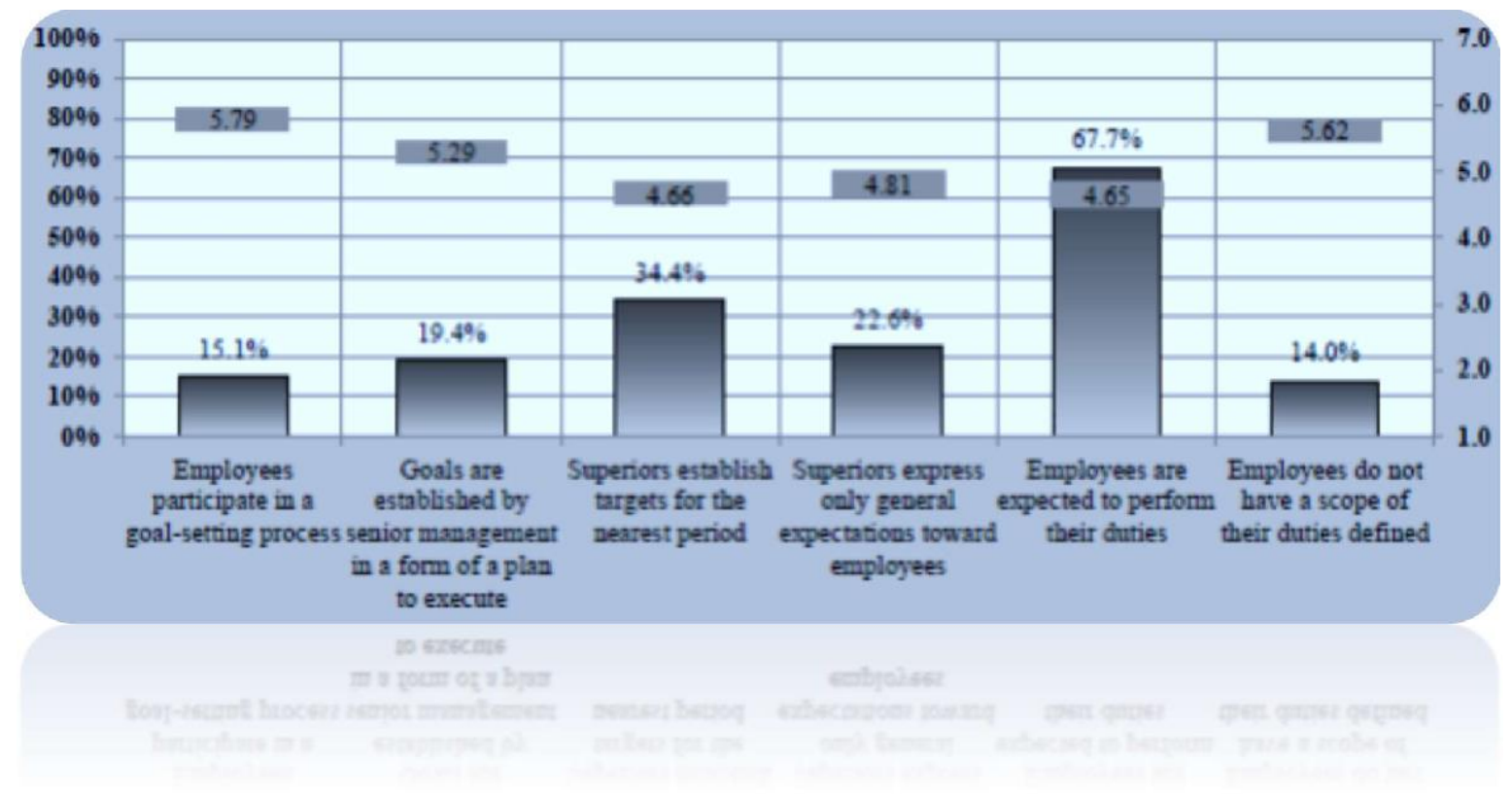

Source: Made by the Author

Concerning formal means of setting goals in SMEs, the most frequent situation was when superiors set goals for the nearest periods (reported in $34.4 \%$ of cases). This is a similar level to that found in large companies. Formalized plans set by managers were found in $19.4 \%$ of SMEs. This was a much lower share than in the case of large companies $(55.8 \%)$. Finally, participatory planning was reported by $15.1 \%$ of SMEs, which was again much lower than that of large firms $(30.2 \%)$. In both groups, however, this was evaluated positively. Taking the three formalized planning modes together, it was found that in more than half of the SMEs (55.9\%) and $80.2 \%$ of the large companies, employees had tangible objectives or targets to refer to. This implied the possibility of applying performance-based reward systems. Finally, it should be added that in $14.0 \%$ of SMEs and $18.6 \%$ of large companies, employees did not have a defined scope of duties. Surprisingly, these situations were seen as positive. The descriptive responses showed that the possibility to define one's tasks leads to greater work efficiency and effectiveness and, consequently, to an additional reward for performance.

\section{c) Managerial Feedback:}

The last indicator of participative management analyzed was the existence of employee meetings organized to discuss company performance (Fig. 3). This indicated that managers viewed employees as important contributors to a company's success, not just as order takers. 


\section{Figure 3: Managerial feedback in Cameroonian SMEs}

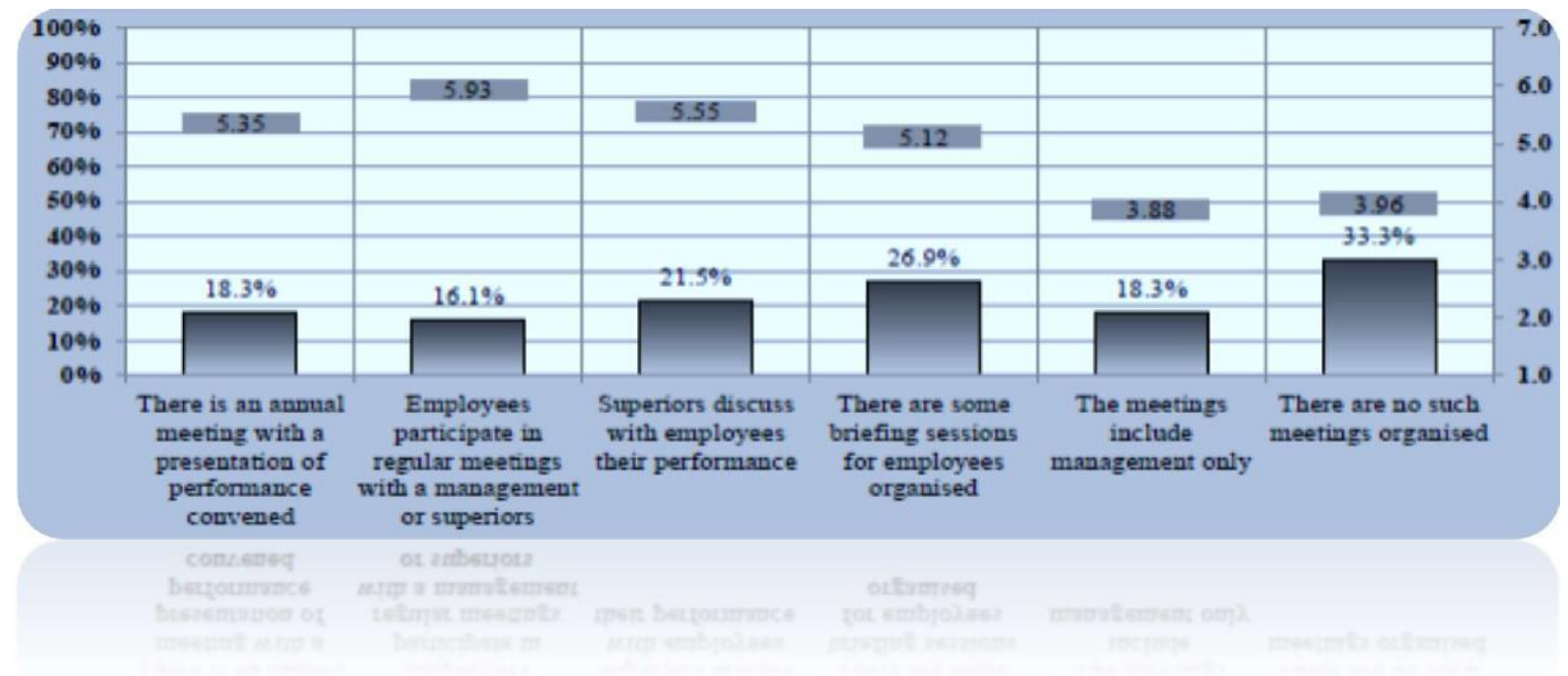

Source: Made by the Author

Employee briefings, held when there were urgent issues to be communicated, proved to be the most frequent form of managerial feedback in SMEs. Such meetings were convened to initiate action, rather than to inform on results. Their formats, duration, and scope of information differed. In some cases, one-way communication was used, in others, employees were allowed to ask questions and could expect answers. The latter form of communication was found to be satisfactory by employees. In larger companies, briefings were popular, but not widespread. However, they were considered the most appropriate. In 34.4\% of SMEs, annual or even more frequent meetings with management were held to discuss company performance. Annual meetings were perceived as the most beneficial. Considering all of the above response options, it can be said that more than half of the SMEs have included their employees in a discussion of business performance. For large companies, the share reached $73.3 \%$. On the other hand, in $18.3 \%$ of Moroccan SMEs, performance-related meetings were only held in management circles. This situation was evaluated as slightly negative. In the case of large firms, the share rose to $33.7 \%$. Obviously, the larger the company, the less practical it would be to include employees in all discussions. However, due to welldeveloped internal communication frameworks, employees received reports in the form of summaries from their superiors. Therefore, no feelings of exclusion were observed.

Finally, in one out of three SMEs, no performance-related meetings were held, which led to mixed feelings among employees. In some cases, employees wanted to know more, while in others, they relied on informal communication or monitored a company's situation by observing customer orders, for example. A similar situation was reported by only $5.8 \%$ of large companies and was considered unacceptable.

\section{Discussion and conclusion:}

Appreciation of inclusive leadership can be seen about employees' satisfaction scores being highest when they were either involved in formulating or at least fully informed of their company's strategic and operational plans. Similarly, a study of Thai companies found that employees who perceived their managers as more democratic and inclusive were generally more satisfied with both their level of participation in decision making and their working conditions (Yukongdi 2010).

However, these most welcome situations were found in only 28.0 percent of the Moroccan SMEs examined and were much more common in larger firms. This research also indicated leadership gaps in many Moroccan SMEs. Employees in one out of four SMEs surveyed indicated that they were not informed by managers about goals or tasks.

Interestingly, employees were not concerned about this information gap because they did not expect anything positive from managers who scrutinize their work. In summary, the purpose of this study was to fill the research gap on the link between inclusive leadership and sustainable competitiveness. In this sense, the study contributes to the literature on participative management and competitive advantage. Indeed, $25 \%$ of the organizations whose employees knew the global strategy were more concerned and involved in its implementation. In terms of involvement in the establishment of objectives, $15 \%$ of the employees of these organizations participated in this process, which conditioned them to be more involved in the implementation and achievement of these objectives because they participated in their development. This had a strong positive impact on the performance of the organization, giving them a competitive advantage over the $67.7 \%$ of organizations in our sample that adopt an autocratic management style and where employees are just expected to perform their tasks. As for managerial feedback, a significant part of the organizations in our sample have a practice of this kind. Indeed, $18.3 \%$ of the 
organizations hold annual meetings with all employees to present, exchange and discuss the performance achieved. $16 \%, 1$ of employees regularly participate in meetings with the organization's top management. $21.5 \%$ of line managers discuss their performance with their employees, and finally $26.9 \%$ of the organizations in our sample organize briefing sessions for their employees.

Participative management aims for organizations to reach a higher level of performance at all levels: economic, organizational, technical, psychological, commercial, etc... Leadership, participation, and culture are so intertwined that without each other they are incomprehensible. Leadership and organization generate a certain culture so that no jump in time is possible. We cannot escape the current dominant culture, just as we cannot transplant managerial or organizational models developed elsewhere. Each person has his or her place within the culture of the organization to which he or she belongs, just as the latter provides the framework and even the measure of individual success. We believe that participative management aims at collectivism because there are many alternative ideas due to the contribution of the members of the organization and there is also less chance of making wrong decisions.

Within this type of management, the focus is on exploiting the ideas generated by employees and colleagues to decide to bring about the best result and efficiency of the organization.

From this point of view, our research has emphasized the competitive advantage generated by applying participatory management to organizations to achieve the efficiency of economic activities. We also consider that participatory management is characterized by the dynamism and complexity of economic activities, technical and scientific development, the need to establish and use material and moral incentives to ensure full agreement of the interests of all parties involved. In conclusion, participatory management can become the real source of sustainable competitive advantage for the organization. In the current situation of technological evolution, organizations must be open to trying to find new development opportunities and should not wish to take a back seat to economic competitors.

\section{Bibliography :}

[1].Detert et Burris (2007). ER 2007, Leadership Behavior and Employee Voice: Is the Door Really Open? Acad. Manag. J.,50, 4 (August 2007), 869-884. DOI 10,5465/AMJ.2007.26279183

[2].Drucker, PF (1999). Realităţile lumii de mâine, (Bucarest : Publishing company Teora, 44, 85-86.

[3].Drucker, PF (1993). Inovaţia şi sistemul antreprenorial, (Bucarest : Publishing company encyclopédique, 87, 129.

[4].Dyczkowska et al (2018). le controle de gestion des start-up - des efforts fragmentés ou un cadre unifié ? 56, 33- 34

[5].Emmert et Taher (1992). Professionnels du secteur public : les effets des emplois publics sur motivation, satisfaction au travail et implication au travail, Un m. Rév. de l'administration publique.22, 1 (mars 1992), 3748. DOI $=10.1177 / 027507409202200103$

[6].G, Lupu FA, (2012). Microeconomic application, (Ploieşti: Publishing company Karta Graphik, 8, 53 -54.

[7].Kim (2002) Participatory Management and Job Satisfaction: Lessons for Management Leadership 231-241. $\mathrm{DOI}=10.1111 / 0033-3352.00173$

[8].Maxwell, John C, (2005) Cele 17 legi ale muncii în echipă, (Bucarest : Publishing company Amaltea, 22, 4445. Organizaţii şi comportament organizaţional, (Iaşi : Publishing company Polirom, 283.

[9].Pitkänen et Lukka 2011). Trois dimensions du feedback formel et informel dans la comptabilité managériale. Manag. Account. Rés.22, 2 (juin 2011), 125-137. DOI =https://doi.org/10.1016/j.mar.2010.10.004

[10]. Porter M, (1985). Competitive advantage of nations, (New York: Free Press), 30, 67.

[11]. Ridderstrale J., Nordstrom H. (2007). Entreprise géniale, (Bucarest : Publishing company Publica, 87.

[12]. Yukongdi (2010). A study of Thai employees' preferred leadership style. Asia-Pac. Business Review. 16, 12 (Jan. 2010), 161-181. DOI =0.180/13602380903168962

[13]. Willson W, (2015) Notele stenografiate ale lui Woodrow Wilson, www.bookcity.rad/librariata.

[14]. Wimalasiri and Kouzmin (2000). A comparative study of employee involvement initiatives in Hong Kong and the United States, 23? 44-45 